\title{
Evaluation of the efficacy and safety of a new device for eye drops instillation in patients with glaucoma
}

This article was published in the following Dove Press journal:

Clinical Ophthalmology

23 February 2015

Number of times this article has been viewed

\author{
Daniela M Junqueira' \\ Flavio S Lopes ${ }^{1,2}$ \\ Fabiola C de Souza' \\ Syril Dorairaj ${ }^{3}$ \\ Tiago S Prata ${ }^{1,2}$ \\ 'Glaucoma Unit, Hospital Medicina \\ dos Olhos, Osasco, Brazil; \\ ${ }^{2}$ Department of Ophthalmology, \\ Federal University of São Paulo, \\ São Paulo, Brazil; ${ }^{3}$ Department \\ of Ophthalmology, Mayo Clinic, \\ Jacksonville, FL, USA
}

Correspondence: Tiago Santos Prata Glaucoma Service, Department of Ophthalmology, Federal University of São Paulo, Rua Eloi Cândido Lopes, 294 Osasco, São Paulo, Brazil

Tel +55 II 36830404

Fax +55 II 2659 I738

Email t.prata0807@gmail.com
Objective: This study evaluated the efficacy and safety of a new device (Eyedrop ${ }^{\circledR}$ ) designed for eye drop instillation in patients with and without glaucoma.

Methods: This prospective study included consecutive patients with glaucoma and healthy participants. After a complete eye examination and determination of baseline intraocular pressure (IOP), topical hypotensive medication was introduced in both eyes, and the Eyedrop ${ }^{\circledR}$ delivery device (a plastic device in which the bottle with eye drops is inserted) was made available to all participants (with video and written instructions) for use in one eye, randomly chosen. In the second phase, all patients were evaluated by an experienced examiner for IOP determination, investigation of possible associated side effects, and ease of instilling eye drops (by a visual analog scale [VAS]; 0-10).

Results: Thirty two participants (mean age $42.3 \pm 16.2$ years) were evaluated. Of these, $44 \%$ had glaucoma. There was no significant difference in mean IOP variation when comparing the eye using $(-3.9 \pm 2.9 \mathrm{mmHg})$ or not using the device $(-3.3 \pm 2.6 \mathrm{mmHg} ; P=0.36)$. The subjective rating of the facility of drops instillation was significantly higher with the Eyedrop ${ }^{\circledR}$ applicator (VAS $=7.6 \pm 1.6$ ) than without it $(\mathrm{VAS}=6.2 \pm 1.8 ; P<0.01$ ), with a higher frequency of positive device-related evaluations (VAS score $>5$ ) among participants without prior experience with eye drop instillation $(78.6 \%$ [11/14]) versus those already experienced $(66.7 \%$ [12/18]). No difference in the frequency of side effects or in the distribution pattern of fluorescein between eyes was observed ( $P \geq 0.63)$.

Conclusion: Eyedrop ${ }^{\circledR}$ received a better subjective response regarding the ease of instillation of hypotensive eye drops compared to traditional instillation, especially in patients with no previous experience with eye drops. Using the device did not result in any loss of hypotensive effect or increase in the frequency of side effects.

Keywords: glaucoma, eye drops, applicator, therapy adherence

\section{Introduction}

Glaucoma, an optic neuropathy characterized by progressive visual field loss, is currently a leading cause of blindness in the world, regardless of the population studied. ${ }^{1,2}$ According to the World Health Organization, the disease accounts for $12.3 \%$ of blindness, cataracts being the leading cause. ${ }^{2}$ Note that unlike cataracts, blindness from glaucoma is irreversible.

Although a multifactorial disease, elevated intraocular pressure (IOP) remains the most important known risk factor. ${ }^{1,3-5}$ The level of IOP appears to play an important role in the development and progression of the disease even when in the statistically normal range. ${ }^{3,4}$ Thus, it is evident that the main treatment for avoiding disease progression or development in patients with glaucoma or who are suspect is the reduction of IOP. ${ }^{5}$ The three options for IOP reduction are clinical treatment, laser, or incisional surgery. Typically, topical hypotensive medications are used as a first treatment option. Although 
there are safe and effective drugs, most of them present side effects, which can be mild and local (eg, conjunctival hyperemia of prostaglandin analogs), or systemic and more serious (eg, cardiorespiratory effects of beta-blockers). ${ }^{6,7}$ In this context, although fixed combinations seem to be slightly less efficacious than their respective unfixed combinations, the former lead to a lower hyperemia risk. ${ }^{7}$

Another important factor to be considered in relation to glaucoma treatment is patient adherence to proposed therapy. Unfortunately, studies of persistence and adherence in glaucoma treatment show that a significant proportion of patients discontinue their use of newly prescribed therapy within the first year of treatment. ${ }^{8-11}$ We know that the daily use of eye drops requires patient dedication, understanding of the disease severity, and ability to instill the medications. Even though there are educational materials for patients seeking to circumvent some of these problems, many report great difficulty during the instillation of the drops. The main reported hindrances include difficulty in keeping the eyes open, handling the bottle, avoiding the contact of the tip to the globe, and finally getting the drops in the right place. These difficulties often imply the need for additional help to instill the medication. In this context, a device that could simplify daily instillation of the eye drops would be useful to minimize some of these difficulties and increase adherence to topical therapy. The aim of this study was to evaluate the efficacy and safety of a new device (Eyedrop ${ }^{\circledR}$; Vanguard Design, São Paulo, Brazil) for eye drop instillation in patients with and without glaucoma.

\section{Methods}

This interventional protocol adhered to the tenets of the Declaration of Helsinki and was approved by the Institutional Review Board of UNIFIEO in November 2013. In addition, written informed consent was obtained from all participants.

\section{Patients}

In this prospective study, consecutive patients with glaucoma (presence of glaucomatous optic neuropathy associated with characteristic visual field defect) and healthy participants with and without prior experience in placing eye drops were included. Prior experience in eye drop instillation was defined as at least one year of continuous use of at least one topical medication. Exclusion criteria were history of prior ocular trauma or surgery, secondary glaucoma, uncontrolled IOP, advanced disease (vertical cup-to-disk ratio $\geq 0.8$ or fixation threat in visual field testing), presence of any other ocular disease besides glaucoma, and physical inability to handle the device (example: severe rheumatoid arthritis).

Glaucomatous optic neuropathy was defined as cupto-disk ratio $>0.6$, asymmetry between eyes $\geq 0.2$, presence of localized defects of the retinal nerve fiber layer, and/ or neuroretinal rim in the absence of any other anomalies that could explain such findings. Characteristic glaucomatous visual field defect in standard automated perimetry (Humphrey SITA - Standard 24-2; Carl Zeiss Meditec, Dublin, CA, USA) was defined as three or more adjacent points with probability $<5 \%$ (except those on the periphery of the field or directly above and below the blind spot) on the Pattern Deviation graphic, a pattern standard deviation index with a probability $<5 \%$, or glaucoma hemifield test with results outside normal limits.

\section{Procedures}

In the first stage, patients underwent a complete ophthalmic examination (visual acuity, Goldmann applanation tonometry, and fundus examination). Possible signs of intolerance to medication use (conjunctival hyperemia, keratitis, and dry eye signs) were evaluated. The baseline IOP for each patient was defined by the average of three measurements. At the end of the visit, bimatoprost $0.01 \%$ (Lumigan ${ }^{\circledR} \mathrm{RC}$; Allergan, Inc., Irvine, CA, USA), from a small round shaped bottle, was introduced in both eyes for all participants. For those already using hypotensive eye drops, current medications were also maintained. The Eyedrop ${ }^{\circledR}$ delivery device was made available to all participants for use in only one eye, in a randomized order. As on-site training prior to medication dispensing using the device, a 3-minute video clip demonstrating how to use the device properly was initially presented. Then, each patient used the device once at the office, supervised by a physician. Finally, a handout was given with written instructions and illustrations.

Eyedrop $^{\circledR}$ is a plastic device with blunt edges, easy to handle, in which the bottle is inserted (Figure 1). To instill drops, the bottle base is pushed after positioning the applicator on the orbit. There is no contact of the applicator or the bottle with the globe. Based on its design and working mechanism, the device could be useful to help patients to overcome some of the previously cited difficulties, such as keeping their eyes open, avoiding contact of the tip to the globe, and finally getting the drops in the globe, and not in the periocular region.

In the second stage of study, held between 10 and 15 days after the first for glaucoma patients and on the same day (6 hours apart) for healthy volunteers, all patients were 

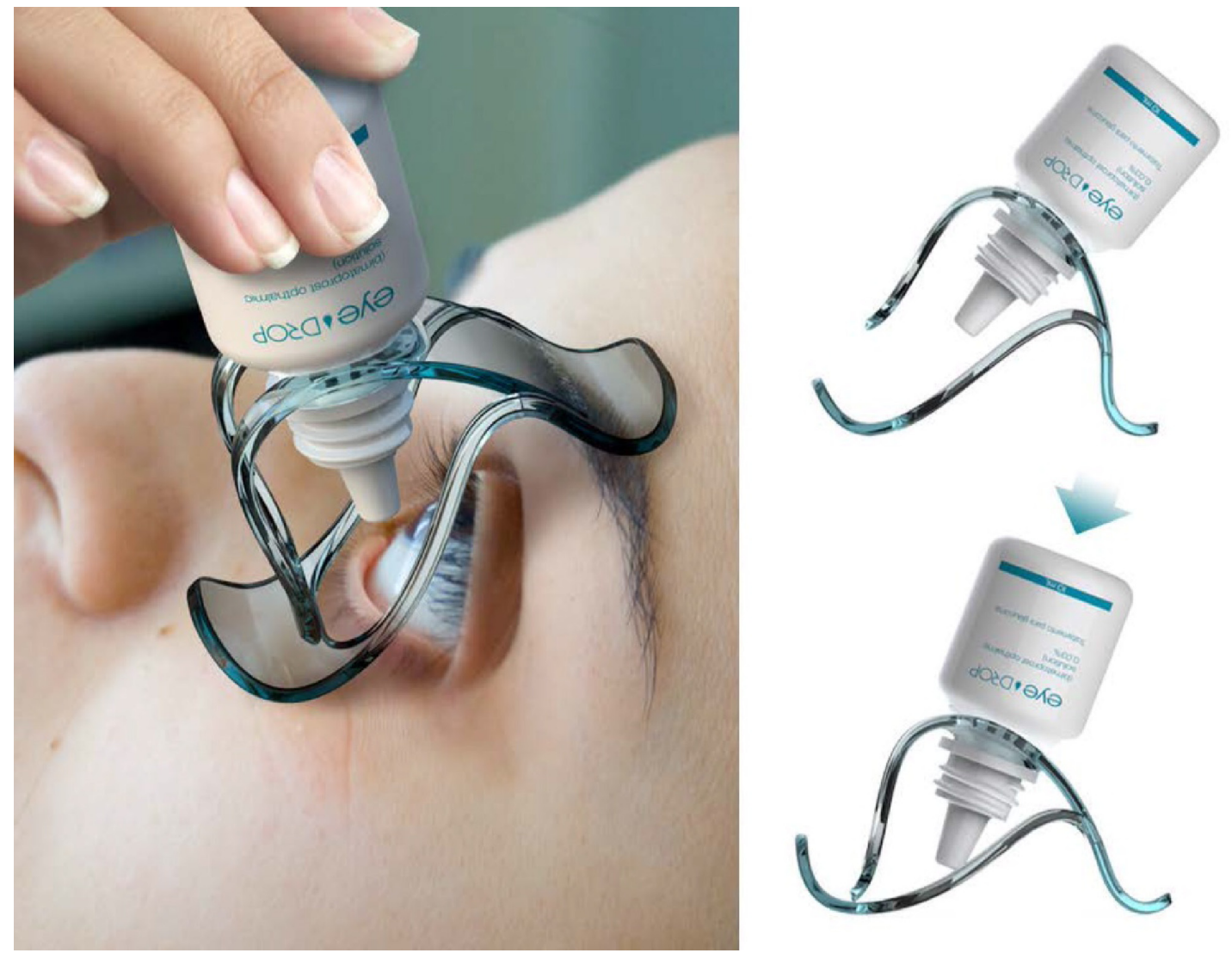

Figure I Eyedrop ${ }^{\circledR}$ ocular medication delivery device.

evaluated by an experienced examiner (blinded to which eye was chosen for applicator use) for IOP determination and investigation of possible associated side effects. To evaluate the ease of instilling the eye drops, a visual analog scale (VAS) (scores ranging from 0-10) was used. In order to investigate whether the drops were being properly instilled, on that same day, each patient was asked to instill fluorescein eye drops in both eyes, the applicator being used in only one eye (choice made at random). The examiner, again masked to which eye was chosen for applicator use, subjectively assessed the pattern of distribution of fluorescein (the presence or absence of the drops at the bottom of the lacrimal sac and possible inadequate instillation in the periocular region).

\section{Statistical analysis}

Descriptive analysis was used to present the demographic and clinical data. The paired $t$-test was used to compare the IOP values with and without the use of the applicator. Differences in VAS scores between eyes were investigated using the Wilcoxon (signed-rank) test. The frequency of side effects between eyes (with and without the applicator) was compared using the McNemar test. For a sample power of
$80 \%$ ( $\beta$ value of 0.20 ) and $\alpha$ value of 0.05 , we would need 26 patients to detect an IOP difference of $2 \mathrm{mmHg}$ (assuming a standard deviation of $2.5 \mathrm{mmHg}$ ) between eyes with and without the applicator. Computerized statistical analysis was performed using MedCalc software (MedCalc Inc., Mariakerke, Belgium), and statistical significance was set at $P<0.05$.

\section{Results}

A total of 32 participants (mean age $42.3 \pm 16.2$ years) were evaluated. Of these, $44 \%$ had glaucoma. The majority of participants were women (72\%) and white (66\%), and 56\% had prior experience with eye drop instillation. Glaucomatous patients were significantly older (mean age, 62.2 \pm 12.1 years; range, 42-82 years) than healthy individuals (mean age, $29.2 \pm 11.9$ years; range, $20-65$ years; $P<0.01$ ).

There was no significant difference in mean IOP variation when comparing the eye on which the applicator was used $(-3.9 \pm 2.9 \mathrm{mmHg})$ and the eye on which traditional instillation was used $(-3.3 \pm 2.6 \mathrm{mmHg} ; P=0.36)$. The subjective rating of the facility of drops instillation was significantly higher with the use of applicator (VAS $=7.6 \pm 1.6$ ) than without it 
(VAS $=6.2 \pm 1.8 ; P<0.01)$. There was a higher frequency of positive device-related evaluations (VAS score $>5$ ) among participants without prior experience with eye drop instillation $(78.6 \%[11 / 14])$ versus those already experienced (66.7\% [12/18]).

Conjunctival hyperemia was the most common side effect in both groups, being observed in $25 \%$ of the eyes for which the delivery device was used and in $21.9 \%$ of those for which the device was not used. Punctate keratitis was also frequent, being observed in $12.5 \%$ of the eyes for which the device was used and in $9.4 \%$ of those for which the device was not used. There were no side effects specifically related to the device (such as ocular or periocular trauma or corneal/conjunctival abrasion). No difference in the frequency of side effects or the distribution pattern of fluorescein between eyes was observed $(P \geq 0.63)$. Finally, among participants with negative evaluations about the delivery device (VAS score $\leq 5$ ), the most common complaint was finding the right placement of the device on the orbit.

\section{Discussion}

When it comes to glaucoma management, patient adherence to topical therapy, which although essential to control the disease, is often insufficient. Evaluating the usefulness of a new device for placing drops in eyes of patients with and without glaucoma, we found a better response from the participants when asked to compare the use of the applicator to the conventional instillation of eye drops. No loss of the hypotensive effect of the medication or increased occurrence of side effects was observed. We believe that these results will add to the existing measures to increase patients' adherence to glaucoma treatment, facilitating the correct use of medications, especially for those with greater difficulty and no previous experience, and hence aiding in disease control. This pilot study is the first clinical evaluation of this new device.

In the literature, the main causes related to poor adherence include a lack of awareness about the disease and irreversible damage, ${ }^{12}$ number of drugs used, impact on family income, ${ }^{13,14}$ side effects, patients' forgetfulness, older age, inability to instill eye drops, problems in handling the bottle, and not having someone to help. ${ }^{14-16}$ At least some of these problems could be minimized with the use of a device for proper instillation of hypotensive eye drops.

In the few studies carried out on the use of eye drops and improvement of patient compliance through a delivery device, the most studied device has been the XAL-Ease delivery system (Pfizer Ophthalmics, New York, USA). In comparison with the conventional use of Xalatan and Xalacom eye drops (both from Pfizer Ophthalmics), different studies showed significant benefits with the use of the device. ${ }^{17,18}$ Semes and Shaikh ${ }^{17}$ found better use of the drops with the device (greater number of drops per bottle) when compared to conventional use. The authors attributed their results to a more uniform individual volume of each drop obtained with the device. ${ }^{17}$ In another study, with a more robust design (multicenter, prospective, randomized, crossover), Nordmann et $a l^{18}$ observed that the use of the device halved the need for additional help to instill eye drops as compared to conventional use. In addition, the risk of the tip of the eye drop bottle touching the globe was significantly reduced. After one month, more than $70 \%$ of the patients reported being satisfied with using XAL-Ease, without significant side effects. ${ }^{18}$ Although our study has a different design and has focused on other aspects related to the use of a delivery device, we believe that our data corroborate those described above, as approximately $72 \%$ of our patients had a positive response to the use of the Eyedrop ${ }^{\circledR}$ device. It is noteworthy that unlike the XAL-Ease, which is designed only for the application of the two abovementioned medications (from Pfizer Ophthalmics), the Eyedrop ${ }^{\circledR}$ device can be used for instillation of different eye drops, with various bottle shapes. Although we consider this as a significant advantage, it should be emphasized that even though the device is suitable for most types of bottles in the market, it cannot be used either with multi-dose bottles with the ABAK filter system or with preservative-free single-dose units (small containers). Finally, although an internet search (google. com) revealed that there are other commercially available devices for instilling eye drops, we did not find any related scientific articles currently published.

This pilot study has some limitations that should be considered when interpreting its results. The study had a relatively small sample (although it was satisfactory from a statistical point of view through the sample calculation for a power of $80 \%$ ), had a short follow-up period, and evaluated only one medication (monotherapy). Therefore, our results should not be extrapolated for patients under two or more topical medications. Moreover, there is the possibility of positive bias in favor of the device, as the individual stimulus generated by the introduction of new equipment could lead to a greater commitment to the use of the medication (regardless of the effectiveness of the applicator itself). Finally, we know that in studies of this type, the fact that the patients know that they are being monitored may lead to an improvement 
in adherence to treatment. ${ }^{19}$ Although this is an important factor, we believe that the paired comparison nature of our study probably minimized this type of influence.

\section{Conclusion}

In this pilot study, a better subjective response was reported regarding the ease of instillation of hypotensive eye drops using the Eyedrop ${ }^{\circledR}$ delivery device compared to traditional instillation, especially in patients with no previous experience with eye drops. The use of the device neither resulted in loss of the hypotensive effect of the medication, nor did it increase the frequency of side effects. Even though we have not directly assessed the long-term IOP control and stability of the disease, we believe our findings can have a positive impact on these aspects, since the improvement in patient adherence to treatment could result in a better IOP control and lower risk of progression over time. Further studies with larger sample sizes and longer follow-up are necessary in order to better investigate such aspects.

\section{Acknowledgments}

The authors received material from Vanguard Design, São Paulo, Brazil for this study. This paper was presented in part at the Annual Meeting of the Brazilian Society of Ophthalmology, 2014.

\section{Disclosure}

The authors received material from Vanguard Design. Vanguard Design also paid the publication fee from Clinical Ophthalmology. The authors report no other conflicts of interest in this work.

\section{References}

1. Weinreb RN, Khaw PT. Primary open-angle glaucoma. Lancet. 2004; 363(9422):1711-1720.

2. Resnikoff S, Pascolini D, Etya'ale D, et al. Global data on visual impairment in the year 2002. Bull World Health Organ. 2004;82(11):844-851.

3. The effectiveness of intraocular pressure reduction in the treatment of normal-tension glaucoma. Collaborative Normal-Tension Glaucoma Study Group. Am J Ophthalmol. 1998;126(4):498-505.

Clinical Ophthalmology

\section{Publish your work in this journal}

Clinical Ophthalmology is an international, peer-reviewed journal covering all subspecialties within ophthalmology. Key topics include: Optometry; Visual science; Pharmacology and drug therapy in eye diseases; Basic Sciences; Primary and Secondary eye care; Patient Safety and Quality of Care Improvements. This journal is indexed on
4. Comparison of glaucomatous progression between untreated patients with normal-tension glaucoma and patients with therapeutically reduced intraocular pressures. Collaborative Normal-Tension Glaucoma Study Group. Am J Ophthalmol. 1998;126(4):487-497.

5. Kass MA, Heuer DK, Higginbotham EJ, et al. The Ocular Hypertension Treatment Study: a randomized trial determines that topical ocular hypotensive medication delays or prevents the onset of primary openangle glaucoma. Arch Ophthalmol. 2002;120(6):701-713.

6. Ostergaard Laursen S, Bjerrum P. Timolol eyedrop-induced severe bronchospasm. Acta Med Scand. 1982;211(6):505-506.

7. Quaranta L, Biagioli E, Riva I, et al. Prostaglandin analogs and timololfixed versus unfixed combinations or monotherapy for open-angle glaucoma: a systematic review and meta-analysis. J Ocul Pharmacol Ther. 2013;29(4):382-389.

8. Shaya FT, Mullins CD, Wong W, Cho J. Discontinuation rates of topical glaucoma medications in a managed care population. Am J Manag Care. 2002;8(10 suppl):S271-S277.

9. Fiscella RG. Persistency with glaucoma medication. Am J Ophthalmol. 2004;138(6):1093-1094.

10. Dasgupta S, Oates V, Bookhart BK, Vaziri B, Schwartz GF, Mozaffari E. Population-based persistency rates for topical glaucoma medications measured with pharmacy claims data. Am J Manag Care. 2002;8(10 suppl):S255-S261.

11. Reardon G, Schwartz GF, Mozaffari E. Patient persistency with topical ocular hypotensive therapy in a managed care population. Am J Ophthalmol. 2004;137(1 suppl):S3-S12.

12. Van Buskirk EM. The compliance factor. Am J Ophthalmol. 1986; 101(5):609-610.

13. Amaral Filho JM, Moreira RAR, Silva SML, et al. [Monthly cost of antiglaucomatous drugs in Brazil] Custo mensal de medicações anti-glaucomatosas no Brasil. Arq Bras Oftalmol. 1999;62:123-126. Portuguese.

14. Kass MA, Gordon M, Meltzer DW. Can ophthalmologists correctly identify patients defaulting from pilocarpine therapy? Am J Ophthalmol. 1986;101(5):524-530.

15. Costa VP, Vasconcellos JP, Pelegrino M, Kara José N. [Analysis of the technique of instillation of drops by glaucoma patients] Análise da técnica de instilação do colírio em pacientes glaucomatosos. Rev Bras Oftalmol. 1995;54:523-528. Portuguese.

16. Sleath B, Robin AL, Covert D, Byrd JE, Tudor G, Svarstad B. Patientreported behavior and problems in using glaucoma medications. Ophthalmology. 2006;113(3):431-436.

17. Semes L, Shaikh AS. Evaluation of the Xal-Ease latanoprost delivery system. Optometry. 2007;78(1):30-33.

18. Nordmann JP, Baudouin C, Bron A, et al. Xal-Ease: impact of an ocular hypotensive delivery device on ease of eyedrop administration, patient compliance, and satisfaction. Eur J Ophthalmol. 2009;19(6):949-956.

19. Feinstein AR. On white-coat effects and the electronic monitoring of compliance. Arch Intern Med. 1990;150(7):1377-1378.

PubMed Central and CAS, and is the official journal of The Society of Clinical Ophthalmology (SCO). The manuscript management system is completely online and includes a very quick and fair peer-review system, which is all easy to use. Visit http://www.dovepress.com/ testimonials.php to read real quotes from published authors. 